\title{
Fractional urinary fluoride excretion of 6-7-year-old children attending schools in low-fluoride and naturally fluoridated areas in the UK
}

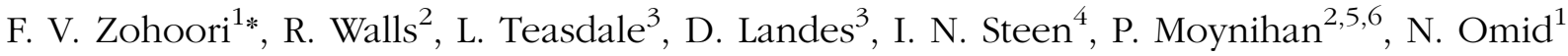 \\ and A. Maguire ${ }^{2}$ \\ ${ }^{1}$ School of Health and Social Care, Teesside University, Middlesbrough TS1 3BA, UK \\ ${ }^{2}$ Centre for Oral Health Research, School of Dental Sciences, Newcastle University, Newcastle upon Tyne, UK \\ ${ }^{3}$ County Durham Primary Care Trust, County Durham, UK \\ ${ }^{4}$ Institute of Health and Society, Newcastle University, Newcastle upon Tyne, UK \\ ${ }^{5}$ Institute for Ageing and Health, Newcastle University, Newcastle upon Tyne, UK \\ ${ }^{6}$ Human Nutrition and Research Centre, Newcastle University, Newcastle upon Tyne, UK \\ (Submitted 1 March 2011 - Final revision received 12 July 2012 - Accepted 12 July 2012 - First published online 14 September 2012)
}

\section{Abstract}

$\mathrm{F}$ is an important trace element for bones and teeth. The protective effect of $\mathrm{F}$ against dental caries is well established. Urine is the prime vehicle for the excretion of F from the body; however, the relationship between F intake and excretion is complex: the derived fractional urinary $\mathrm{F}$ excretion (FUFE) aids understanding of this in different age groups. The present study aimed to investigate the relationships between (1) total daily F intake (TDFI) and daily urinary F excretion (DUFE), and (2) TDFI and FUFE in 6-7-year-olds, recruited in low-F and naturally fluoridated (natural-F) areas in north-east England. TDFI from diet and toothbrushing and DUFE were assessed through $\mathrm{F}$ analysis of duplicate dietary plate, toothbrushing expectorate and urine samples using a F-ion-selective electrode. FUFE was calculated as the ratio between DUFE and TDFI. Pearson's correlation and regression analysis were used to investigate the relationship between TDFI and FUFE. A group of thirty-three children completed the study; twenty-one receiving low-F water $(0 \cdot 30 \mathrm{mg} F / \mathrm{l})$ and twelve receiving natural-F water $(1.06 \mathrm{mg} \mathrm{F} / \mathrm{l})$ at school. The mean TDFI was 0.076 (sD 0.038 ) and 0.038 (sD 0.027$) \mathrm{mg} / \mathrm{kg}$ per $\mathrm{d}$ for the natural-F and low-F groups, respectively. The mean DUFE was 0.017 (sD 0.007) and 0.012 (sD 0.006) mg/kg per d for the natural-F and low-F groups, respectively. FUFE was lower in the natural-F group (30\%) compared with the low-F group (40\%). Pearson's correlation coefficient for (1) TDFI and DUFE was $+0.22(P=0 \cdot 22)$ and for (2) TDFI and FUFE was $-0.63(P<0 \cdot 001)$. In conclusion, there was no correlation between TDFI and DUFE. However, there was a statistically significant negative correlation between FUFE and TDFI.

Key words: Fluoride: Urinary excretion: Dietary intake

$\mathrm{F}$ is a trace element which, following absorption from the gastrointestinal tract, is rapidly incorporated into calcified tissues that contain $99 \%$ of body F. Although the influence of $\mathrm{F}$ on bone metabolism is less well defined, the protective effect against dental caries is well established ${ }^{(1,2)}$. However, several recent studies in industrialised and developing countries have shown an increase in the prevalence of dental fluorosis in populations from communities with and without water fluoridation ${ }^{(3,4)}$, which may suggest that the threshold of $\mathrm{F}$ exposure for maximising caries prevention while minimising the potential risk of dental fluorosis has been exceeded. Obtaining the best balance between substantial caries reduction and the avoidance of unsightly dental enamel fluorosis is of critical importance to public health planners.
According to recent epidemiological surveys in the UK, 39\% of 5 -year-olds ${ }^{(5)}$ and $33 \%$ of 11 -year-olds ${ }^{(6)}$ had evidence of dental caries experience involving dentine, while dental caries experience was even higher (48\%) in 14-year-old English children ${ }^{(7)}$. The relatively high prevalence of dental caries in UK children highlights the need for primary prevention programmes such as fluoridation schemes. Estimations of total daily $\mathrm{F}$ intake at an individual and community level are key when recommendations for $\mathrm{F}$ use are being considered. Ingestion of $\mathrm{F}$ may occur from water, foods, toothpaste and other therapeutic agents. Increasingly, residence in a non-fluoridated community does not automatically assure low $\mathrm{F}$ intake, nor does living in a fluoridated community mean adequate or high $\mathrm{F}$ intake, since food, drink or even bottled water produced in a fluoridated area may be

Abbreviations: BW, body weight; DUFE, daily urinary fluoride excretion; FUFE, fractional urinary fluoride excretion; TDFI, total daily fluoride intake.

*Corresponding author: F. V. Zohoori, fax +441642 342770, email v.zohoori@tees.ac.uk 
transported to a non-fluoridated area and vice versa ${ }^{(8)}$. In addition, some dietary factors can increase or reduce the absorption and excretion of $\mathrm{F}^{(9)}$, making body $\mathrm{F}$ retention an important yet variable consideration. In the absence of high concentrations of certain cations (e.g. $\mathrm{Ca}$ and $\mathrm{Al}$ ), almost $90 \%$ of $\mathrm{F}$ ingested with food is absorbed from the gastrointestinal tract and passed rapidly into the blood. The remaining $10 \%$ is excreted with the faeces. Urine is the prime vehicle for excretion of $\mathrm{F}$ that is absorbed but not taken up by bones. It is estimated that children under 6 years of age excrete approximately $50 \%$ of their ingested $\mathrm{F}$ through the urine ${ }^{(10)}$. $\mathrm{F}$ in the urine has been suggested as a suitable non-invasive biomarker for $\mathrm{F}$ exposure ${ }^{(11)}$ because collection of information on dietary $\mathrm{F}$ and that ingested from toothbrushing, at a community level, is time consuming, costly and requires a high level of expertise. Furthermore, varying degrees of gastrointestinal $\mathrm{F}$ absorption from different sources of $\mathrm{F}$ intake, such as diet and dental care products, might limit the value of estimated F exposure with regard to its systemic effect. Given these limitations, measurement of urinary $\mathrm{F}$ excretion has been recommended as an adequate method for monitoring fluoridation schemes ${ }^{(11,12)}$.

Studies of $\mathrm{F}$ intake and urinary excretion have shown a wide variation in urinary $\mathrm{F}$ excretion as a proportion of $\mathrm{F}$ intake, ranging from 32 to $80 \%$ in children ${ }^{(13-21)}$ as summarised in Table 1 . There is, therefore, a need for more assessment of the suitability and validity of urinary $F$ excretion for monitoring fluoridation schemes as well as for predicting total $\mathrm{F}$ intake. The aims of the present study were therefore to investigate the relationships between (1) total daily $\mathrm{F}$ intake (TDFI) and daily urinary F excretion (DUFE), and (2) TDFI and fractional urinary $\mathrm{F}$ excretion (FUFE) in children.

\section{Materials and methods}

The present study was conducted according to the guidelines laid down in the Declaration of Helsinki and all procedures involving human subjects/patients were approved by the County Durham and Tees Valley 2 Research Ethics Committee (ethics no. 09/H0908/9). Written informed consent was obtained from all participants/patients.

\section{Study population and recruitment}

The study was conducted in areas of the north-east of England where the water supply was not artificially fluoridated. Before commencing the study, associated 'Research and Development' approval was also obtained from the relevant Primary Care Trust's Research Management and Governance Unit. The Director of Children's Services Directorate and Local Education Authorities were also contacted and informed of the study.

Parents of children were contacted through the schools which agreed to take part in the study. The inclusion criteria were as follows: healthy children aged 6-7 years who were lifelong residents of the area; children not receiving any professionally applied topical $\mathrm{F}$ therapy.

Participating children were not randomly selected but were those for whom parental permission had been obtained. In total, forty-four informed written consents were obtained from parents of the children who met the study inclusion criteria. Following the recruitment, each child and his/her parents were visited twice at their home.

In visit 1, the weight of the child, without shoes and jacket, was measured to the nearest $0 \cdot 1 \mathrm{~kg}$ using a portable digital balance (SOEHNLE Slim Design Linea; ADE (GmbH \& Co.)). Their height was also measured to the nearest $0 \cdot 1 \mathrm{~cm}$ using a stadiometer (SOEHNLE MZ10020; ADE (GmbH \& Co.)). BMI was then calculated as weight ( $\mathrm{kg}$ ) divided by height squared $\left(\mathrm{m}^{2}\right)$.

At visit 1, parents were provided with a bag that contained equipment required for collection of urine and food (duplicate plate) samples and instructions on how to collect these samples. Information on the toothbrushing habits of the child was also collected and a home tap water sample taken for subsequent $\mathrm{F}$ analysis.

\section{Dietary assessment}

Dietary $\mathrm{F}$ intake of the children was monitored by the 'duplicate plate' method as described by Guha-Chowdhury et al. ${ }^{\text {(22) }}$. The parents were asked to maintain the usual dietary habits of their children and duplicate portions of all food and drink items as precisely as possible by observing and replicating

Table 1. Summary of the literature on total daily fluoride intake (TDFI), daily urinary fluoride excretion (DUFE) and fractional urinary fluoride excretion (FUFE) by age group and country

\begin{tabular}{|c|c|c|c|c|c|c|}
\hline Country & Age (years) & $n$ & F exposure & TDFI (mg/d) & DUFE $(\mathrm{mg} / \mathrm{d})$ & FUFE $(\%)^{*}$ \\
\hline \multirow[t]{3}{*}{ Sweden ${ }^{(20)}$} & & & Water (1 mg F/l) & & & \\
\hline & $0.19-0.54$ & 5 & Breast-fed & 0.011 & 0.030 & 359 \\
\hline & $0.15-0.31$ & 4 & Formula-fed & 0.927 & 0.359 & 39 \\
\hline$U K^{(19)}$ & $1-3$ & 7 & Water $(0.81 \mathrm{mg} \mathrm{F} / \mathrm{l})$ & 0.71 & 0.33 & 48 \\
\hline $\mathrm{USA}^{(13)}$ & $3-4$ & 10 & Water (optimal) & 0.33 & 0.28 (including faeces) & Not reported \\
\hline USA $^{(21)}$ & $0.19-0.89$ & 4 & Formula-fed & 0.190 & 0.144 & 78 \\
\hline Chile ${ }^{(15)}$ & $3-5$ & 20 & Water $(0.5-0.6 \mathrm{mg} \mathrm{F} / \mathrm{l})$ & 1.02 & 0.358 & 35.5 \\
\hline Germany $^{(16)}$ & $3-6$ & 11 & Salt $F$ tablets $(0.25-1 \mathrm{mg} / \mathrm{d})$ & 0.931 & 0.476 & 51.5 \\
\hline $\operatorname{Iran}^{(14)}$ & 4 & 78 & Water $(0.30-0.39 \mathrm{mg} \mathrm{F} / \mathrm{l})$ & 0.428 & 0.339 & 80 \\
\hline Colombia $^{(17)}$ & $4-5$ & 96 & Table salt $(180-220 \mathrm{mg} \mathrm{F} / \mathrm{kg}$ ) & 1.55 & 0.414 & 33 \\
\hline \multirow[t]{4}{*}{$\mathrm{UK}^{(18)}$} & $6-7$ & & Water & & & \\
\hline & & 18 & $0.08 \mathrm{mg} \mathrm{F} / \mathrm{l}$ & 0.736 & 0.277 & 44 \\
\hline & & 8 & $0.47 \mathrm{mg} \mathrm{F} / \mathrm{l}$ & 0.883 & 0.333 & 40 \\
\hline & & 5 & $0.82 \mathrm{mg} \mathrm{F} / \mathrm{l}$ & 1.043 & 0.420 & 32 \\
\hline
\end{tabular}

*DUFE as a percentage of TDFI. 
the actual consumed amounts by the children over $24 \mathrm{~h}$. They were asked to remove parts of food items not normally eaten such as bones, fruit skin, cores, etc., before placing them in the container provided. They were also asked to collect drinks separately in the plastic bottles provided.

Each parent was also supplied with a $1 \mathrm{~d}$ food diary and accompanying instructions, for the recording of food and drink consumed on the day the duplicate plate was collected. This was done so that the researchers could cross-reference the information in the diary with the duplicate plate analysis for validation purposes. For those children who were at school during the sample collection period, researchers who were on-site during the school day obtained a duplicate of the child's school dinner and noted the items consumed. Any snacks and drinks including free school fruit and food consumed at breakfast clubs/breaks were also included in the duplicate plate.

\section{Assessment of ingested toothpaste}

$\mathrm{F}$ intake from ingested toothpaste during toothbrushing was estimated using the method described by Maguire et al. ${ }^{(18)}$. In brief, expectorated toothpaste/saliva samples were obtained during a tooth brushing session, which took place either at the child's school or at their home. Children provided their own toothpaste and each child was provided with a new toothbrush (Aquafresh Big Teeth for 6-7-year-olds or Aquafresh Milk Teeth for 3-4-year-olds). Toothbrushes were weighed before and after the child or parent dispensed toothpaste. Any toothbrushing expectorate was collected in a small plastic sample collection pot together with the water used to rinse the toothbrush.

\section{$24 \mathrm{~h}$ urine collection}

Collection of the $24 \mathrm{~h}$ urine sample started on the same day as the duplicate plate collection (day 1). Parents were advised to record the time of the child's first voided urine sample. All subsequent urine, up to and including the first passing of urine on the following day (day 2), was collected for the $24 \mathrm{~h}$ collection. During school hours, urine was collected by the child, supported by trained study researchers. Each child's voided urine sample was passed to the researchers for storage until the full $24 \mathrm{~h}$ sample had been collected.

At visit 2, which was conducted on day 2, the day following duplicate plate collections and after the final collection of urine, all samples were collected from the family home. At the same time, the researchers went through the food diary with the parent and child and checked it against the items in the duplicate plate collection.

\section{Sample preparation and analysis}

Collected samples were then taken to the F laboratory for processing. Urine collected at home and school (where applicable) was mixed together to produce a pooled sample and the volume recorded. Expectorated saliva/toothpaste samples were vortexed for $30 \mathrm{~s}$. Collected samples of home and school drinks were also mixed together and the volume recorded. Food collected at home and school was mixed, weighed and then homogenised using an industrial blender (Thermomix TM31; Vorwek). Finally, three aliquots each of urine, expectorated saliva, homogenised foods, water and drinks were taken and stored at $-20^{\circ} \mathrm{C}$ for further analysis.

Urine, water and drink samples were analysed, in triplicate, for $\mathrm{F}$ by a direct $\mathrm{F}$ analysis method using a F-ion-selective electrode (Model 9609; Orion Research) coupled to a potentiometer (Model 720A), after sample buffering with total ionic strength adjustment buffer (III) ${ }^{(23)}$. Food and expectorated saliva/toothpaste samples were analysed, in triplicate, for $\mathrm{F}$ concentration after overnight hexamethyldisiloxane-facilitated diffusion at room temperature using the F-ion-selective electrode and meter ${ }^{(24)}$. Of these samples, $10 \%$ were re-analysed for $\mathrm{F}$ concentration, giving a mean reproducibility of $99.6 \%$.

The creatinine concentration of each urine sample was measured by the Jaffe $\operatorname{method}^{(25)}$ using an autoanalyser (ADIVA 1650; Siemens Medical Solutions Diagnostics).

\section{Data preparation and analysis}

F intake from toothpaste ingestion during toothbrushing was estimated by subtracting the $\mathrm{F}$ content of expectorated saliva/toothpaste from the amount of $\mathrm{F}$ initially loaded onto the brush during toothbrushing. $\mathrm{F}$ ingestion per brushing was then multiplied by the frequency of brushing (information at visit 1 ), to calculate the daily $\mathrm{F}$ intake from toothpaste for each child. Daily dietary $\mathrm{F}$ intake was estimated from the weight of each duplicate plate sample and the F concentrations of their aliquots. Since none of the children used any $F$ supplements, total daily $F$ intake (TDFI, in $\mathrm{mg} / \mathrm{d}$ ) was calculated by adding $\mathrm{F}$ intake from diet and $\mathrm{F}$ ingested from toothpaste.

Completeness of the $24 \mathrm{~h}$ urine samples was checked against two criteria: (1) the lower limits of 5 and $9 \mathrm{ml} / \mathrm{h}$ for urinary flow rate in $<6$ - and $\geq 6$-year-olds ${ }^{(11)}$, respectively, and (2) a lower limit of $11.3 \mathrm{mg} / \mathrm{kg}$ body weight (BW) per $\mathrm{d}$ for creatinine excretion ${ }^{(26)}$. Any sample that did not meet either of these criteria was excluded from further analysis.

DUFE $(\mathrm{mg} / \mathrm{d})$ was estimated from the $24 \mathrm{~h}$ urine volume and $\mathrm{F}$ concentration of the urine sample. TDFI and DUFE were also calculated based on body weight ( $\mathrm{mg} / \mathrm{kg} \mathrm{BW}$ per $\mathrm{d}$ ). FUFE (\%) was then calculated from the following equation:

$$
\text { FUFE }(\%)=(\text { DUFE } / \text { TDFI }) \times 100 \text {. }
$$

The data were analysed descriptively using SPSS version 17.0. The percentage of TDFI from diet and FUFE were calculated for each child, individually, before calculating the sample mean and standard deviation. The correlations between TDFI and DUFE and FUFE were examined by regression analysis and Pearson's correlation.

\section{Results}

Of the forty-four recruited, thirty-four children completed all aspects of the study. Data from one child were excluded 
Table 2. Fluoride concentration of water supply, age, height, weight and BMI of children by fluoride area and sex (Mean values and standard deviations)

\begin{tabular}{|c|c|c|c|c|c|c|c|c|c|c|}
\hline & \multicolumn{2}{|c|}{$\begin{array}{l}\text { Natural-F* } \\
\text { area }(n 12)\end{array}$} & \multicolumn{2}{|c|}{$\begin{array}{c}\text { Low-F† area } \\
(n 21)\end{array}$} & \multicolumn{2}{|c|}{ Girls ( $n 17)$} & \multicolumn{2}{|c|}{ Boys (n 16) } & \multicolumn{2}{|c|}{$\begin{array}{l}\text { All children } \\
\text { (n 33) }\end{array}$} \\
\hline & Mean & SD & Mean & SD & Mean & SD & Mean & SD & Mean & SD \\
\hline Age (years) & $6 \cdot 6$ & 0.3 & $6 \cdot 8$ & 0.6 & $6 \cdot 8$ & 0.5 & $6 \cdot 8$ & 0.7 & $6 \cdot 8$ & 0.6 \\
\hline Height (cm) & $119 \cdot 8$ & $6 \cdot 3$ & $125 \cdot 9$ & $12 \cdot 2$ & $125 \cdot 5$ & $13 \cdot 4$ & 121.9 & $6 \cdot 8$ & $123 \cdot 7$ & $10 \cdot 7$ \\
\hline Weight (kg) & $22 \cdot 8$ & $3 \cdot 2$ & $25 \cdot 4$ & $4 \cdot 1$ & $24 \cdot 1$ & $2 \cdot 8$ & $24 \cdot 8$ & 4.9 & 24.5 & 3.9 \\
\hline BMI $\left(\mathrm{kg} / \mathrm{m}^{2}\right)$ & $15 \cdot 8$ & $1 \cdot 3$ & $16 \cdot 1$ & $2 \cdot 7$ & $15 \cdot 5$ & $2 \cdot 0$ & $16 \cdot 6$ & $2 \cdot 6$ & $16 \cdot 0$ & $2 \cdot 3$ \\
\hline
\end{tabular}

because the urine sample was incomplete. Therefore, the final sample was thirty-three children.

$\mathrm{F}$ analysis of school water supply showed a mean $\mathrm{F}$ concentration of $0.30(\mathrm{SD} 0 \cdot 12) \mu \mathrm{g} / \mathrm{ml}$ for twenty-one children (low-F group) and $1.06(\mathrm{SD} 0.11) \mu \mathrm{g} / \mathrm{ml}$ for twelve children (natural-F group). The mean $\mathrm{F}$ concentration of home water supply for the low-F group was $0 \cdot 20$ (SD 0.10) and 0.49 (SD $0.32) \mu \mathrm{g} / \mathrm{ml}$ for the natural-F group.

The mean age of the low-F and natural-F groups was 6.8 (sD 0.6) and 6.6 (sD 0.3) years, respectively (Table 2). Although the average body weight of the low-F group was heavier $(25.4 \mathrm{~kg})$ than that of the natural-F group $(22.8 \mathrm{~kg})$, the BMI values were similar: $16 \cdot 1$ and $15 \cdot 8 \mathrm{~kg} / \mathrm{m}^{2}$, respectively.

Data on $\mathrm{F}$ intake from diet and toothpaste ingestion are presented in Table 3. The mean dietary $\mathrm{F}$ intake for the natural-F group was 0.578 (SD 0.298) $\mathrm{mg} / \mathrm{d}$, while for the low-F group it was 0.341 (sD 0.254$) \mathrm{mg} / \mathrm{d}$. For the natural-F group, drinks provided $56 \%$ of dietary $\mathrm{F}$ intake; in the low-F group, they provided $46 \%$ of dietary $\mathrm{F}$.

Approximately $71 \%$ of children used a toothpaste labelled as children's toothpaste and $71 \%$ also reported undertaking toothbrushing twice per $d$. On average, children ingested $51 \%$ of the total amount of toothpaste dispensed onto the toothbrush; however, the range was very wide, from 2 to $97 \%$. The mean $\mathrm{F}$ intake from toothbrushing was 1.130 (SD 0.820 ) and $0.606(\mathrm{SD} 0.562) \mathrm{mg} / \mathrm{d}$ for the natural-F and low-F groups, respectively (Table 3 ).

None of the children in the present study took any $\mathrm{F}$ tablets or supplements. Diet and toothpaste ingestion were therefore the only sources of $\mathrm{F}$ intake for these children. The mean total daily $\mathrm{F}$ intake was $1.707(\mathrm{SD} 0.799) \mathrm{mg} / \mathrm{d}$ for the natural-F group and $0.945(\mathrm{sD} 0.621) \mathrm{mg} / \mathrm{d}$ for the low-F group. On a $\mathrm{mg} / \mathrm{kg} \mathrm{BW}$ basis, this represented 0.076 (SD 0.038) and 0.038 (SD 0.027$) \mathrm{mg} / \mathrm{kg}$ BW per $\mathrm{d}$ for the natural-F and low-F groups, respectively. $\mathrm{F}$ intake from diet represented 41 and $44 \%$ of total daily $\mathrm{F}$ intake for children in the natural- $\mathrm{F}$ and low-F groups, respectively.

Mean urine volumes for the natural-F and low-F groups were 547 (sD 304) and 607 (sD 314) ml, respectively (Table 3). Based on body weight, mean urinary $\mathrm{F}$ excretion was 0.017 (SD 0.007) $\mathrm{mg} / \mathrm{kg} \mathrm{BW}$ per $\mathrm{d}$ for the natural-F group and 0.012 (SD 0.006) $\mathrm{mg} / \mathrm{kg}$ BW per $\mathrm{d}$ for the low-F group. FUFE was slightly lower in the natural-F group (30\%) compared with the low-F group (40\%). The relationship between TDFI and DUFE is presented in Fig. 1. No statistically significant correlation was found between TDFI and DUFE. There was a strong negative correlation between FUFE and TDFI (Pearson's correlation -0.63), which was highly statistically significant $(P<0.001$; Fig. 2).

\section{Discussion}

The knowledge base regarding the usefulness of urinary F excretion as a tool in epidemiological surveillance for prediction of total $\mathrm{F}$ intake in children is inadequate. The present study demonstrated that urinary $\mathrm{F}$ might not be a reliable estimator for $\mathrm{F}$ intake in children aged 6-7 years as suggested previously.

In the present study, no child used $\mathrm{F}$ supplements or $\mathrm{F}$ tablets, and therefore diet and dentifrice ingestion were the main sources of total daily $F$ intake for all children. In populations using $\mathrm{F}$ toothpaste, diet has been reported as contributing up to almost $80 \%$ of ingested $\mathrm{F}^{(27)}$. However, in the present study, toothpaste was the major component of TDFI,

Table 3. Total daily fluoride intake (TDFI) from diet and toothpaste ingestion, daily urinary fluoride excretion (DUFE) and fractional urinary fluoride excretion (FUFE, \%) for all participants

(Mean values and standard deviations)

\begin{tabular}{|c|c|c|c|c|}
\hline & \multicolumn{2}{|c|}{$\begin{array}{l}\text { Natural- } \mathrm{F}^{\star} \text { area } \\
\quad(n 12)\end{array}$} & \multicolumn{2}{|c|}{$\begin{array}{l}\text { Low-F† area } \\
\quad(\text { n 21) }\end{array}$} \\
\hline & Mean & SD & Mean & SD \\
\hline \multicolumn{5}{|l|}{ Daily F intake } \\
\hline From diet $(\mathrm{mg} / \mathrm{d})$ & 0.578 & 0.298 & 0.341 & 0.254 \\
\hline Food $(\mathrm{mg} / \mathrm{d})$ & 0.229 & 0.166 & 0.187 & 0.236 \\
\hline Drink (mg/d) & 0.349 & 0.263 & $0 \cdot 154$ & $0 \cdot 137$ \\
\hline \multicolumn{5}{|l|}{ From toothpaste ingestion } \\
\hline $\mathrm{mg} / \mathrm{d}$ & $1 \cdot 130$ & 0.820 & 0.606 & 0.562 \\
\hline $\mathrm{mg} / \mathrm{kg}$ BW per d & 0.050 & 0.104 & 0.024 & 0.024 \\
\hline \multicolumn{5}{|l|}{ TDFI† } \\
\hline $\mathrm{mg} / \mathrm{d}$ & $1 \cdot 707$ & 0.799 & 0.945 & 0.621 \\
\hline $\mathrm{mg} / \mathrm{kg}$ BW per d & 0.076 & 0.038 & 0.038 & 0.027 \\
\hline Diet as a proportion of TDFI (\%) & 41 & 27 & 44 & 27 \\
\hline \multicolumn{5}{|l|}{ Urinary F excretion } \\
\hline Volume of urine $(\mathrm{ml} / \mathrm{d})$ & 547 & 304 & 607 & 314 \\
\hline \multicolumn{5}{|l|}{ DUFE } \\
\hline $\mathrm{mg} / \mathrm{d}$ & 0.393 & 0.209 & 0.297 & $0 \cdot 131$ \\
\hline $\mathrm{mg} / \mathrm{kg}$ BW per d & 0.017 & 0.007 & 0.012 & 0.006 \\
\hline FUFE (\%) & 30 & 21 & 40 & 22 \\
\hline
\end{tabular}

BW, body weight.

${ }^{*} 1.06 \mu \mathrm{g} \mathrm{F} / \mathrm{ml}$.

$+0.30 \mu \mathrm{g} \mathrm{F} / \mathrm{ml}$.

$\ddagger$ None of the children used $\mathrm{F}$ supplements or $\mathrm{F}$ tablets. 


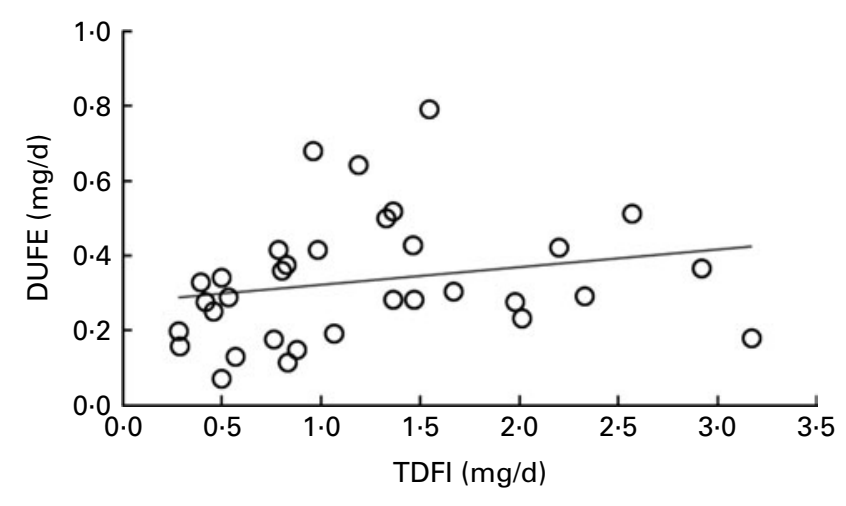

Fig. 1. Relationship between total daily fluoride intake (TDFI) and daily urinary fluoride excretion (DUFE) for thirty-three children aged 6-7 years. Pearson's coefficient $+0.22(P=0.22)$. DUFE $=0.047($ TDFI $)+0.274 . R^{2} 0.05$.

in both natural-F and low-F areas. Generally, toothpaste can make the largest percentage contribution to TDFI in children younger than 6 years, as they are not in full control of their swallowing reflex and therefore might swallow significant amounts of toothpaste unintentionally ${ }^{(28)}$. At this age, the crowns of permanent teeth are still undergoing calcification and are therefore susceptible to the uptake of $\mathrm{F}$ into enamel apatite, and as a result, excess $\mathrm{F}$ intake can result in dental fluorosis ${ }^{(29)}$. The literature shows a wide variation in the contribution of $\mathrm{F}$ toothpaste to TDFI ranging from $22 \%$ for 6 -year-olds in Iowa $^{(30)}$ to $69 \%$ for $4-5$-year-olds in Puerto Rico $^{(31)}$. The differences in the contribution of toothpaste to TDFI in different studies could be explained by the differences in children ages, the $\mathrm{F}$ concentrations of the toothpastes used and the diet consumed, as well as the data collection methods and techniques used to measure $\mathrm{F}$ intake from these sources.

In the present study, mean daily $\mathrm{F}$ intake from drinks was substantially higher in the natural-F area compared with that in the low-F area, which confirms that the impact of $\mathrm{F}$ concentration of home water supply on total $\mathrm{F}$ intake may be decreasing due to the trend towards consumption of foods and drinks made outside the home ${ }^{(9)}$.

The mean TDFI of children in the natural-F area $(0.076 \mathrm{mg} / \mathrm{kg}$ BW per d) was slightly higher than the suggested optimum range of $0.05-0.07 \mathrm{mg} / \mathrm{kg} \mathrm{BW}$ per $\mathrm{d}$ for optimal dental health benefit, whereas for children living in the low-F area, the TDFI $(0.038 \mathrm{mg} / \mathrm{kg}$ BW per $\mathrm{d})$ was below the optimum range. Therefore, in low-F communities, children might benefit from a community-based preventive programme such as milk fluoridation or supervised toothbrushing at schools.

The mean DUFE when expressed on a body-weight basis for the two groups of children was fairly similar, despite the considerable difference in TDFI between the groups (Table 3). The mean FUFE of children in the natural-F group (30\%) was lower than the corresponding value for children in the low-F area (40\%). The estimated FUFE varies widely in the literature from $32 \%$ for 6-7-year-olds to $359 \%$ for breast-fed infants (Table 1 ). There are several possible explanations for the wide range of reported FUFE. Almost $50 \%$ of ingested $\mathrm{F}$ is absorbed from the stomach; however, several substances influence the degree of absorption. High dietary levels of fat may increase the absorption of ingested $\mathrm{F}$ since the fat reduces the rate of gastric emptying. In addition, foods containing appreciable amounts of divalent or trivalent cations (e.g. $\mathrm{Ca}, \mathrm{Mg}, \mathrm{Fe}$ ) may reduce the degree of absorption due to the formation of insoluble complexes. The kidneys are the major route for the removal of $\mathrm{F}$ from the body and urinary $\mathrm{pH}$ can influence the renal clearance of $\mathrm{F}$. When the tubular fluid is acidic, more ionic $\mathrm{F}$ is converted to hydrogen fluoride which is diffusible across the renal tubular epithelium. Differences in the composition of diet and the altitude of residence can significantly influence urinary $\mathrm{pH}$, and consequently F excretion ${ }^{(9)}$. Age, kidney maturation and body size (existing skeletal mass) are also important variables in $\mathrm{F}$ retention.

In a recent study, the relationship between urinary F excretion and TDFI was examined using previously published data on $\mathrm{F}$ intake and excretion in children and adults $^{(32)}$. This study showed a positive linear relationship between urinary $\mathrm{F}$ excretion and $\mathrm{F}$ intake with a slope of +0.35 and intercept of 0.03 in children, suggesting that urinary $\mathrm{F}$ excretion can be used to estimate daily $\mathrm{F}$ intake in children younger than 7 years. However, in the present study, daily urinary $\mathrm{F}$ excretion did not correlate with TDFI, and there was a lower slope of +0.05 and a higher intercept of 0.27 . This result implies that for 6-7-year-old children living in an industrialised country, TDFI cannot be adequately predicted from urinary excretion of $\mathrm{F}$, in contrast to the results of the former study. However, there are two main differences between these two studies; the present study was based on the data from only thirty-three children with a narrow age range (6-7-year-olds), whereas the former study included pooled data from 212 children with a wide age range from $0 \cdot 19$ to 7 years. The stage of bone maturation can influence the rate of uptake of $\mathrm{F}$ into bones and teeth. Since the rate of uptake is greater into newly formed bones, $\mathrm{F}$ retention would be greater during periods of rapid growth and development ${ }^{(9)}$. The differences in urinary $\mathrm{F}$ excretion between different age groups of young children may be also attributed to the differences in their diet as well as dietary habits. For example, the absorption of $\mathrm{F}$ from ingested water is almost $100 \%$; however, when $\mathrm{F}$ is taken with milk, the degree of absorption

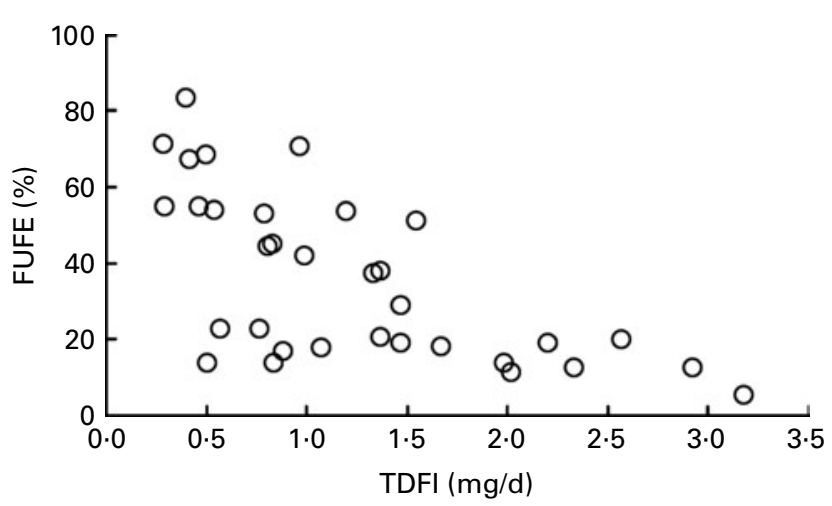

Fig. 2. Relationship between total daily fluoride intake (TDFI) and fractional urinary fluoride excretion (FUFE) for thirty-three children aged 6-7 years. Pearson's coefficient $-0.63(P<0.001)$. 
might be reduced by up to $50 \%$ due to the formation of $\mathrm{CaF}_{2}$ which has a low aqueous solubility ${ }^{(33)}$.

The negative correlation between FUFE and TDFI observed in the present study implies a higher $\mathrm{F}$ retention with increasing $\mathrm{F}$ intake. However, Fig. 2 suggests that FUFE remains almost constant above a TDFI of approximately $1.6 \mathrm{mg} / \mathrm{d}$ with the estimated FUFE reaching a limiting constant value independent of the magnitude of TDFI.

In conclusion, there was a statistically significant negative correlation between FUFE and TDFI, but no correlation between TDFI and DUFE, in 6-7-year-olds. Therefore, DUFE might not provide the basis for a reliable estimate of total F intake for 6-7-year-old children. However, this relationship should be investigated further in different age groups, separately, with larger sample sizes, in order to establish any conclusion on the use of DUFE as a reliable estimate of TDFI in children.

\section{Acknowledgements}

The present study was funded by The Borrow Foundation. A. M. and F. V. Z. designed the research and drafted the manuscript. R. W. and L. T. collected the information and samples. N. O. analysed the samples. I. N. S. provided the statistical support for the study. I. N. S. and F. V. Z. analysed the data. P. M. and D. L. were involved in the conceptualisation of the research and in the manuscript drafting. All authors read and approved the final manuscript. The authors have no conflict of interest to disclose.

\section{References}

1. Featherstone JDB (1999) Prevention and reversal of dental caries: role of low level fluoride. Community Dent Oral Epidemiol 27, 31-40.

2. McDonagh SM, Whiting PF, Wilson PM, et al. (2000) Systematic review of water fluoridation. BMJ 321, 855-859.

3. Szpunar S \& Burt B (1990) Fluoride exposure in Michigan schoolchildren. J Public Health Dent 50, 18-23.

4. Pendrys DG \& Stamm JW (1990) Relationship of total fluoride intake to beneficial effects and enamel fluorosis. $J$ Dent Res 69, 529-538.

5. Pitts NB, Boyles J, Nugent ZJ, et al. (2007) The dental caries experience of 5-year-old children in Great Britain (2005/6). Surveys co-ordinated by the British Association for the study of community dentistry. Community Dent Health $\mathbf{2 4}$, 59-63.

6. Pitts NB, Boyles J, Nugent ZJ, et al. (2006) The dental caries experience of 11-year-old children in Great Britain. Surveys co-ordinated by the British Association for the study of community dentistry. Community Dent Health 23, 44-57.

7. Pitts NB, Boyles J, Nugent ZJ, et al. (2004) The dental caries experience of 14-year-old children in England and Wales. Surveys co-ordinated by the British Association for the study of community dentistry. Community Dent Health 21, $45-57$.

8. Heilman JR, Kiritsy MC, Levy SM, et al. (1999) Assessing fluoride levels of carbonated soft drinks. J Am Dent Assoc 130, 1593-1599.
9. Buzalaf MAR \& Whitford GM (2011) Fluoride metabolism. In Fluoride and the Oral Environment: Monographs in Oral Science. Basel: Karger.

10. World Health Organisation (1994) Fluoride and Oral Health. WHO Expert Committee on Oral Health Status and Fluoride Use Report Series no. 846. Geneva: WHO.

11. Marthaler TM (1999) Monitoring of Renal Fluoride Excretion in Community Preventive Programmes on Oral Health. Geneva: World Health Organization.

12. Marthaler TM, Steiner M, Menghini G, et al. (1995) Urinary fluoride excretion in children with low fluoride intake or consuming fluoridated salt. Caries Res 29, 26-34.

13. Brunetti A \& Newbrun E (1983) Fluoride balance of children 3 and 4 years old. Caries Res 17, 171.

14. Zohouri FV \& Rugg-Gunn AJ (2000) Total fluoride intake and urinary excretion in 4-year-old Iranian children residing in low-fluoride areas. Br J Nutr 83, 15-25.

15. Villa A, Anabalon M \& Cabezas L (2000) The fractional urinary fluoride excretion in young children under stable fluoride intake conditions. Community Dent Oral Epidemiol 28, 344-355.

16. Haftenberger M, Viergutz G, Neumeister V, et al. (2001) Total fluoride intake and urinary excretion in German children aged 3-6 years. Caries Res 35, 451-457.

17. Franco AM, Saldarriaga A, Martignon S, et al. (2005) Fluoride intake and fractional urinary fluoride excretion of Colombian preschool children. Community Dent Health 22, 272-278.

18. Maguire A, Zohouri FV, Hindmarch PN, et al. (2007) Fluoride intake and urinary excretion in 6- to 7-year-old children living in optimally, sub-optimally and nonfluoridated areas. Community Dent Oral Epidemiol 35, 479-488.

19. Zohouri FV, Swinbank CM, Maguire A, et al. (2006) Is the fluoride/creatinine ratio of a spot urine sample indicative of 24-h urinary fluoride? Community Dent Oral Epidemiol 34, 130-138.

20. Ekstrand J, Hardell LI \& Spak CJ (1984) Fluoride balance studies on infants in a 1-ppm-water-fluoride area. Caries Res. 18, 87-92.

21. Ekstrand J, Ziegler EE, Nelson SE, et al. (1994) Absorption and retention of dietary and supplemental fluoride by infants. Adv Dent Res 8, 175-180.

22. Guha-Chowdhury N, Drummond BK \& Smillie AC (1996) Total fluoride intake in children aged 3 to 4 years: a longitudinal study. J Dent Res 75, 1451-1457.

23. Martínez-Mier EA, Cury JA, Heilman JR, et al. (2011) Development of gold standard ion-selective electrode-based methods for fluoride analysis. Caries Res 45, 3-12.

24. Taves D (1968) Separation of fluoride by rapid diffusion using hexamethyldisiloxane. Talanata 15, 969-974.

25. Bonsnes R \& Taussky H (1945) The colorimetric determination of creatinine by the Jaffe reaction. J Biol Chem $\mathbf{1 5 8}$, $581-591$.

26. Remer T, Neubert A \& Maser-Gluth C (2002) Anthropometrybased reference values for 24-h urinary creatinine excretion during growth and their use in endocrine and nutritional research. Am J Clin Nutr 75, 561-569.

27. Levy SM, Warren JJ, Davis CS, et al. (2001) Patterns of fluoride intake from birth to 36 months. J Public Health Dent 61 , $70-77$

28. Maternal and Child Health Bureau (2007) Topical Fluoride Recommendations for High-risk Children Development of Decision Support Matrix. Washington, DC: MCBH. 
29. Robinson C, Connell S, Kirkham J, et al. (2004) The effect of fluoride on the developing tooth. Caries Res 38, $268-276$.

30. Levy SM, Warren JJ \& Broffitt B (2003) Patterns of fluoride intake from 36 to 72 months of age. J Public Health Dent 63, 211-220.

31. Rojas-Sanchez F, Kelly SA, Drake KM, et al. (1999) Fluoride intake from foods, beverages and dentifrice by young children in communities with negligibly and optimally fluoridated water: a pilot study. Community Dent Oral Epidemiol 27, 288-297.

32. Villa A, Anabalon M, Zohouri V, et al. (2010) Relationships between fluoride intake, urinary fluoride excretion and fluoride retention in children and adults: an analysis of available data. Caries Res 44, 60-68.

33. Ekstrand J \& Ehrnebo M (1979) Influence of milk products on fluoride bioavailability in man. Eur J Clin Pharmacol 16, 211-215. 